Research Paper

\title{
The Use of a Whole Animal Biophotonic Model as a Screen for the Angiogenic Potential of Estrogenic Compounds
}

\author{
Ramey C Youngblood ${ }^{1,2}{ }^{\bowtie}$, Marcus McGee ${ }^{5}$, Jean M Feugang1,2, Scott T Willard ${ }^{1,4}$, Peter L Ryan¹,2,3 \\ 1. Facility of Organismal and Cellular Imaging, Mississippi State University, Mississippi State, MS, USA; \\ 2. Department of Animal and Dairy Sciences, Mississippi State University, Mississippi State, MS, USA; \\ 3. Department of Pathology and Population Medicine, College of Veterinary Medicine, Mississippi State University, Mississippi State, MS, USA; \\ 4. Department of Biochemistry and Molecular Biology, Entomology, and Soil Sciences, Mississippi State University, Mississippi State, MS, USA; \\ 5. Department of Animal and Veterinary Science, University of Idaho, Moscow, ID, USA.
}

$\triangle$ Corresponding author: Ramey C Youngblood, Email addresses: RCY: rcy7@msstate.edu, Phone: 662-325-0581; Fax: 662-325-8873.

(c) Ivyspring International Publisher. This is an open-access article distributed under the terms of the Creative Commons License (http://creativecommons.org/ licenses/by-nc-nd/3.0/). Reproduction is permitted for personal, noncommercial use, provided that the article is in whole, unmodified, and properly cited.

Received: 2013.06.24; Accepted: 2014.03.25; Published: 2014.04.07

\begin{abstract}
Background: Vascular endothelial growth factor (VEGF) is essential for normal vascular growth and development during wound repair. VEGF is estrogen responsive and capable of regulating its own receptor, vascular endothelial growth factor receptor-2 (VEGFR-2). Several agricultural pesticides (e.g., methoxychlor) have estrogenic potential that can initiate inappropriate physiological responses in estrogenic-sensitive tissues following exposure in vivo. Thus, the current study was designed to determine whether the VEGFR-2-Luciferase (Luc) reporter transgenic mouse is a useful model for evaluating estrogenic tendencies of methoxychlor by monitoring wound healing via VEGFR-2-mediated gene expression using bioluminescence and real-time imaging technology.

Results: VEGFR-2-Luc gene activity peaked by $\mathrm{d} 7(P<0.00 \mathrm{I})$ in all groups but was not different $(P>0.05)$ between control and estrogen/methoxychlor exposed mice.

Conclusions: Changes in VEGFR-2-Luc gene activity associated with the dermal wound healing process were able to be measured via photonic emission. The increase in vasculature recruitment and formation is paralleled by the increase of VEGFR-2-Luc activity with a peak on day 7. However, estrogen/methoxychlor did not significantly alter wound healing mediated VEGFR-2-Luc gene expression patterns compared to controls. This suggests that the VEGFR-2-Luc transgenic mouse wound model tested in this study may not be optimal for use as a screen for the angiogenic potential of estrogenic compounds.
\end{abstract}

Key words: VEGF; VEGFR-2; Biophotonics; Real-Time Imaging; Methoxychlor; Wound Healing.

\section{Introduction}

Wound healing is an organized response to organ or tissue injury, or part of the normal tissue repair and turnover process that is observed for example, in the female reproductive system. This process is characterized by a complex and diverse set of cellular activities that include acute and chronic inflammation, cell migration, angiogenesis, and matrix deposition [1]. Wound healing models are useful tools for understanding tissue repair and regeneration processes such as angiogenesis, and the cellular activities asso- ciated therein. Angiogenesis, the formation of capillary sprouts from pre-existing blood vessels, is vital to many physiological and pathological processes including cycling of the female reproductive tract, wound healing, and tumor formation. Each of these processes depends on the formation of new blood vessels to deliver oxygen and other required nutrients to newly formed or growing tissues. This neovascularization is highly regulated by vascular endothelial growth factor (VEGF), a specific mitogen for vascular 
endothelial cells [2]

VEGF elicits physiological responses by binding to one of several membrane bound tyrosine kinase receptors including VEGF receptor-1 (VEGFR-1), VEGF receptor-2 (VEGFR-2), and VEGF receptor-3 (VEGFR-3). Of these receptors, VEGFR-2 is the major mitogenic receptor and is necessary for the differentiation and proliferation of endothelial and hematopoietic cells [3]. Evidence that VEGF can regulate its own receptor $[4,5]$ and synchronized expression profiles of VEGF and VEGFR-2 suggests that VEGF acts in a paracrine manner with tight control over receptor expression patterns to regulate local angiogenesis [6, 7]. This relationship of VEGF and its receptor is important when monitoring angiogenesis in discrete areas, such as wound sites.

Furthermore, VEGF has been shown to be regulated by estrogens and pharmacological evidence has demonstrated that this regulation is mediated by transcriptional activation via the estrogen receptor $[8$, 9]. Moreover, evidence to support a role for estrogen regulation of VEGF expression was confirmed by the discovery of sequences for the estrogen response element (ERE) on the VEGF gene that bind the estrogen receptor ER [10]. Given the importance of estrogen in breast and endometrial cancer, and the importance of angiogenesis in these diseases, several studies have shown that both estrogens and anti-estrogens are capable of regulating VEGF expression [11-13]. The skin, whose obvious function is protection, also acts as an endocrine organ. According to receptor distribution and related actions, estrogens exert direct influences on all elements of skin [14]. It has been recognized for many years that estrogens stimulate the synthesis and turnover of collagen in rats [15] and humans [16]. Presence of estrogen receptors in mouse [17] and human [18] skin further emphasize the susceptibility of skin to estrogens. Likewise studies have shown VEGF to be influenced by estrogens in dermal cells in vitro $[19,20]$.

Several agricultural pesticides (e.g., methoxychlor, permethrin, atrazine) in use today have potent estrogenic activities that can initiate an inappropriate physiological response within normal and tumorigenic tissues. In light of this evidence, there is a concern regarding the endocrine disruptive potential of pesticides that possess xenoestrogenic tendencies. Pesticides are used for the control of agricultural and indoor pests, but their ubiquitous use has led to the contamination of food sources, the work place, homes and the environment [21-23]. Methoxychlor (MXC), an organochlorine insecticide, is frequently used as a replacement for the once popular DDT and is approved for use on edible food crops (fruits, vegetables) as well as on animals (dairy and beef cattle) [24].
Methoxychlor is considered relatively safe for human use based on its low acute toxicity (rat oral $\mathrm{LD}_{50} 6,000$ $\mathrm{mg} / \mathrm{kg}$ ). However, methoxychlor is readily metabolized by the liver to the estrogenic metabolite, 2, 2-bis (4-hydroxyphenyll)-1, 1, 1-trichloreoethane (HPTE), and is a very effective competitor of the estrogen receptor [25]. Consequently, female reproductive development may be affected by methoxychlor with varying degrees of severity. Neonatal mice treated with methoxychlor were observed to have precocious vaginal opening, persistent vaginal cornification, increased uterine weight, and epithelial hypertrophy of the vagina and uterus [26].

At issue is the identification of such compounds in an easy, efficient, and timely manner. Physiologically relevant models with a purpose for screening compounds with potential disruptive characteristics are needed to better predict how a given compound may impact the environment. Here, we employ a transgenic mouse wound model to assess its ability to detect endocrine disruptive effects of estrogenic and a xenoestrogenic pesticide compound (i.e. estradiol $17 \beta$, methoxychlor). Given the importance of VEGFR-2 in VEGF regulated pathways, the VEGFR-2-Luc transgenic mouse (Caliper Life Sciences-PerkinElmer, Hopkinton, Mass.) is a unique animal model used to non-invasively monitor VEGFR-2 gene expression, thus indirectly observing the VEGF system in vivo [27], which is extensively involved in the process of neovascularization [2]. The estrogen-sensitive responsiveness of the VEGF system during tissue repair suggests that it might be a useful model endocrine system to evaluate the potentially disruptive tendencies of xenoestrogenic chemicals, in this case agricultural pesticides.

\section{Methods}

\section{Experimental Design}

Thirty-two male 10 to 15 week old FVB/N VEGFR-2-Luc transgenic mice (Caliper Life Sciences-PerkinElmer, Hopkinton, Mass.) were randomly assigned to one of four treatment groups $(n=8)$ : safflower oil alone (Control), estradiol $17 \beta\left(\mathrm{E}_{2} ; 0.05\right.$ $\mathrm{mg} / \mathrm{kg} / \mathrm{d}$ ), methoxychlor low dose (MXC Low; 30 $\mathrm{mg} / \mathrm{kg} / \mathrm{d}$ ), and methoxychlor high dose (MXC High; $150 \mathrm{mg} / \mathrm{kg} / \mathrm{d}$ ). Male animals were used to eliminate or diminish any confounding effects (i.e. cyclical or elevated levels of endogenous $E_{2}$, or photonic emission from reproductive tract) of the highly estrogen sensitive female reproductive system and or highly vascular reproductive tract. On day 0 , mice were anesthetized with isoflurane (1.5-3.0\%), and two sets of 6-mm full-thickness wounds were created on the dorsal aspect of the animal following clipping and 
cleaning with Betadine surgical scrub [28]. The full-thickness wounds were created by placing the animal on its side and taking two through by through skin biopsy punch of the dermis to create two wound sites simultaneously, creating a total of four wounds/mouse. Following surgery, each mouse was imaged at time zero on day 0 while under anesthesia and then returned to the animal room. Animals were housed separately under controlled temperature $\left(22^{\circ} \mathrm{C}\right)$ and photo-period (12h : $12 \mathrm{~h}$ light : dark), with unlimited access to food and water.

\section{Animal Care}

Post-surgery recovery was implemented by keeping animals warm (towel-wrapped) while not undergoing imaging. Analgesia for the mice was provided by the addition of acetaminophen (1.5 $\mathrm{mg} / \mathrm{ml}$ ) to the water for the first seven days of the study. Mice were maintained on a phytoestrogen-free, casein-based rodent diet (Test Diet 8117; Purina, Richmond, IN) to minimize the potential of phytoestrogenic influence on VEGF/VEGFR-2 expression and subsequent wound healing process. This study followed the NRC (1996) Guide for the Care and Use of Laboratory Animals (2002) and was approved by the Mississippi State University Institutional and Animal Care and Use Committee.

\section{Treatment Delivery}

Estradiol $17 \beta$ and methoxychlor were administered daily from day 0 (day of wounding) in $100 \mu \mathrm{l}$ of safflower oil by oral gavage (mimicking real world oral uptake) at respective treatment group doses for a 14-day period. Safflower oil was administered alone as the control treatment $(100 \mu \mathrm{l} / \mathrm{d}$ for $14 \mathrm{~d})$.

\section{Bioluminescent Imaging}

Serial images of photonic emissions were recorded (5-min collection of photons) from wound sites $10 \mathrm{~min}$ after administration of luciferin $(150 \mathrm{mg} / \mathrm{kg}$ i.p.) following initial wound induction on day 0 and on days $2,4,7,9,11$, and 14 post wounding [28] to measure VEGFR-2-Luc reporter driven luciferase activity using an IVIS 100 biophotonic imaging system (Caliper Life Sciences-PerkinElmer, Hopkinton, Mass.). Luciferase activity (i.e., photons/second) was quantified and analyzed using Living Image software (Caliper Life Sciences-PerkinElmer, Hopkinton, Mass.). Regions of interest (ROIs) where created around individual wound sites and photonic emission data obtained from the wound ROIs was used to analyze VEGFR-2-Luc reporter gene activity. During the imaging procedure, animals were anesthetized (1.5-3.0\% isoflurane) and maintained on a $37^{\circ} \mathrm{C}$ heated platform to ensure stability while photonic emissions were recorded from the wound sites. Percent change in wound area was also calculated using Living Image software to monitor the rate of actual wound closure over time.

\section{Dermal Tissue Preparation}

Four mice from each group were euthanized on day 7 and the remaining four on day 14 post-wounding for acquisition of dermal tissue samples. Each mouse had four punch wounds on the dorsal aspect of the animal. Each of these wounds was excised along with approximately $5.0 \mathrm{~mm}$ of the surrounding tissue. Two tissue samples from each mouse were fixed in $10 \%$ formalin and two tissue samples were snap frozen in liquid nitrogen for histopathology and molecular analysis respectively.

\section{Molecular Analysis of VEGF mRNA Expression}

Determination of murine-specific VEGF mRNA from dermal wounds was performed and confirmed using reverse transcription-polymerase chain reaction (RT-PCR). Total RNA from dermal tissue samples was extracted and purified using Trizol reagent according to the manufacturer's instructions (Invitrogen, Carlsbad, CA). Quantitation and purity of RNA preparations was performed by UV spectrophotometry with purity determined by measuring the absorbance 260:280 nm ratio and concentration determined using the Beer-Lambert law. Total RNA from each sample $(2.5 \mu \mathrm{g})$ was reverse transcribed into first-strand cDNA using the MuLV reverse transcriptase and random hexamers provided from the Retroscript kit (Ambion, Austin, TX). The PCR reaction was performed using the resulting cDNA template and proprietary components of the mouse VEGF Relative RT-PCR Kit (Ambion, Austin, TX). Annealing temperatures and cycle numbers were obtained from the Ambion Kit's protocols. Products were resolved by electrophoresis on a $2 \%$ agarose gel. RNA variability was normalized using 18S RNA, which was amplified in a multiplex reaction along with VEGF. Image J was used to quantify band intensities associated with VEGF and 18S RNA. For each sample, the VEGF band intensity was divided by the intensity of the corresponding 18S RNA band. Data are expressed as VEGF mRNA levels as a percent of $18 \mathrm{~S}$ RNA.

\section{Detection of ER $\alpha$ in Dermal Tissue}

Estrogen Receptor a (ERa) mRNA expression in dermal tissue samples was detected using the XpressPack $^{\mathrm{TM}}$ ERa (human, mouse, rat) mRNA Expression Analysis Kit and the XpressPack ${ }^{\mathrm{TM}}$ Luminescent Detection System (Chemicon International, Temecula, CA). The company's specific guidelines and protocols were followed in order to verify presence of ERa mRNA. 


\section{Histology}

Sections $(5 \mu \mathrm{M})$ of fixed, paraffin wax-embedded dermal wound samples were mounted on glass slides. Standard histological protocols for Masson's Trichrome and Factor VIII staining [29] were performed on tissue slides to evaluate collagen content and endothelial cell presence respectively.

\section{Statistical Analysis}

The experimental design is one of repeated measures (multiple measurements in time on each mouse) with subsampling (four measurements per mouse per day treatment combination). The statistical analysis was performed using the PROC MIXED function in SAS version 8.02 (SAS, Cary, NC). The animal was the random-effect component, and effects were considered significant where $P<0.05$.

\section{Results and Discussion}

\section{Real-Time Bioluminescent Monitoring of VEGFR-2 In Vivo}

This study was undertaken to investigate the relevance and value of using biophotonics and real-time imaging technology as a tool to screen for compounds with estrogenic activity. In this experiment we test the efficacy of using the VEGFR-2-Luc transgenic mouse to indirectly monitor VEGF activity via VEGFR-2-Luc gene expression, in conditions influenced by estrogen or an estrogenic compound (i.e. methoxychlor). The rationale for using this animal model was based on three main criteria: 1) the mouse is an established model for wound healing studies in vivo [28], 2) VEGFR-2 is transcriptionally regulated by VEGF during angiogenesis [4, 5], 3) biophotonics technology provides an opportunity to monitor, both in real time and temporally, genes of interest under physiologically relevant experimental conditions.

VEGFR-2 promoter driven gene expression was able to be measured as photonic emission from wound sites. Dorsal bioluminescent images collected from wound sites of VEGFR-2-Luc transgenic mice (Fig 1) showed no significant $(P>0.05)$ effect of $E_{2}$ or MXC treatment on level of VEGFR-2-Luc-mediated gene expression at wound sites compared to control (Fig 2).

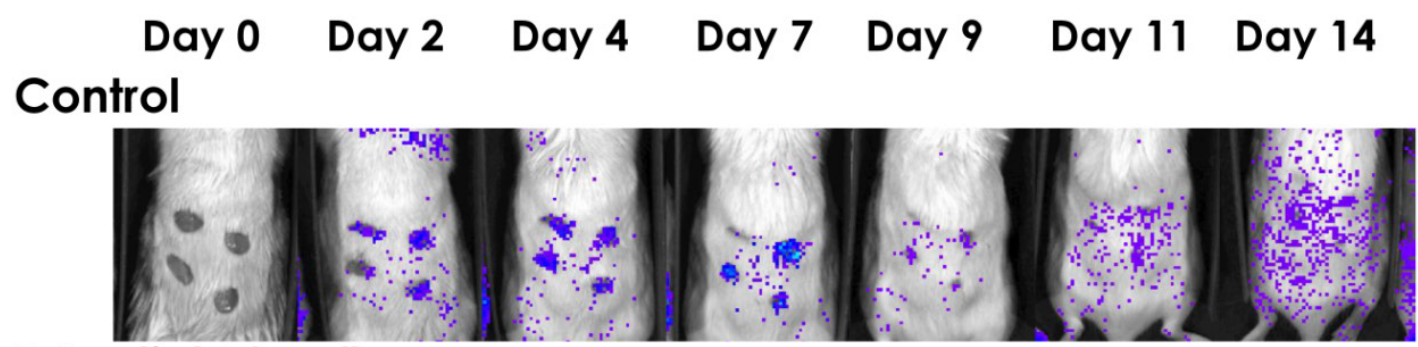

Estradiol $50 \mu \mathrm{g} / \mathrm{kg}$

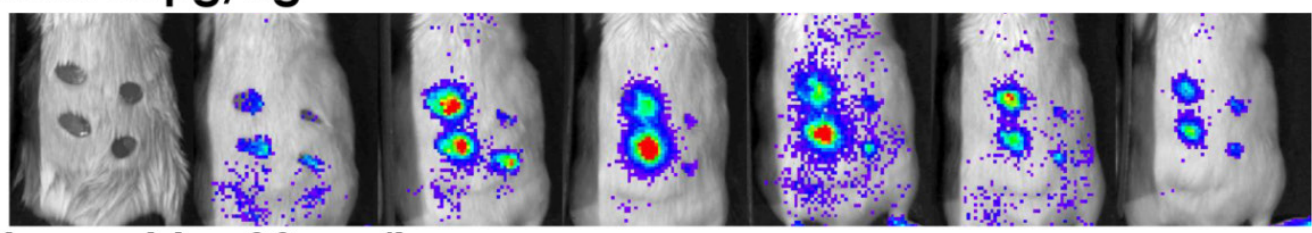

Methoxychlor 30mg/kg

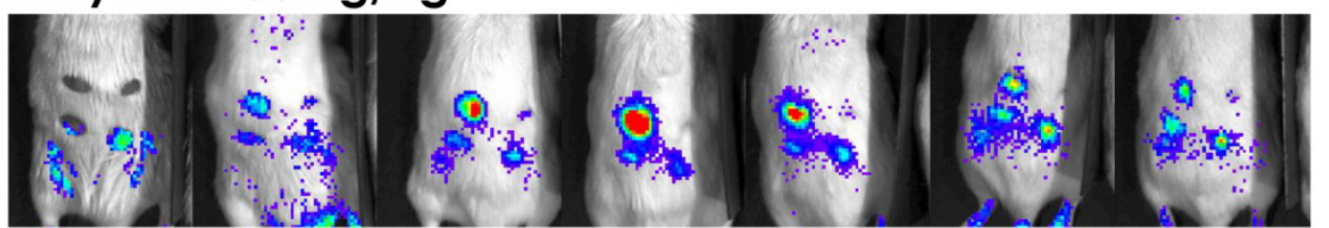

Methoxychlor $150 \mathrm{mg} / \mathrm{kg}$
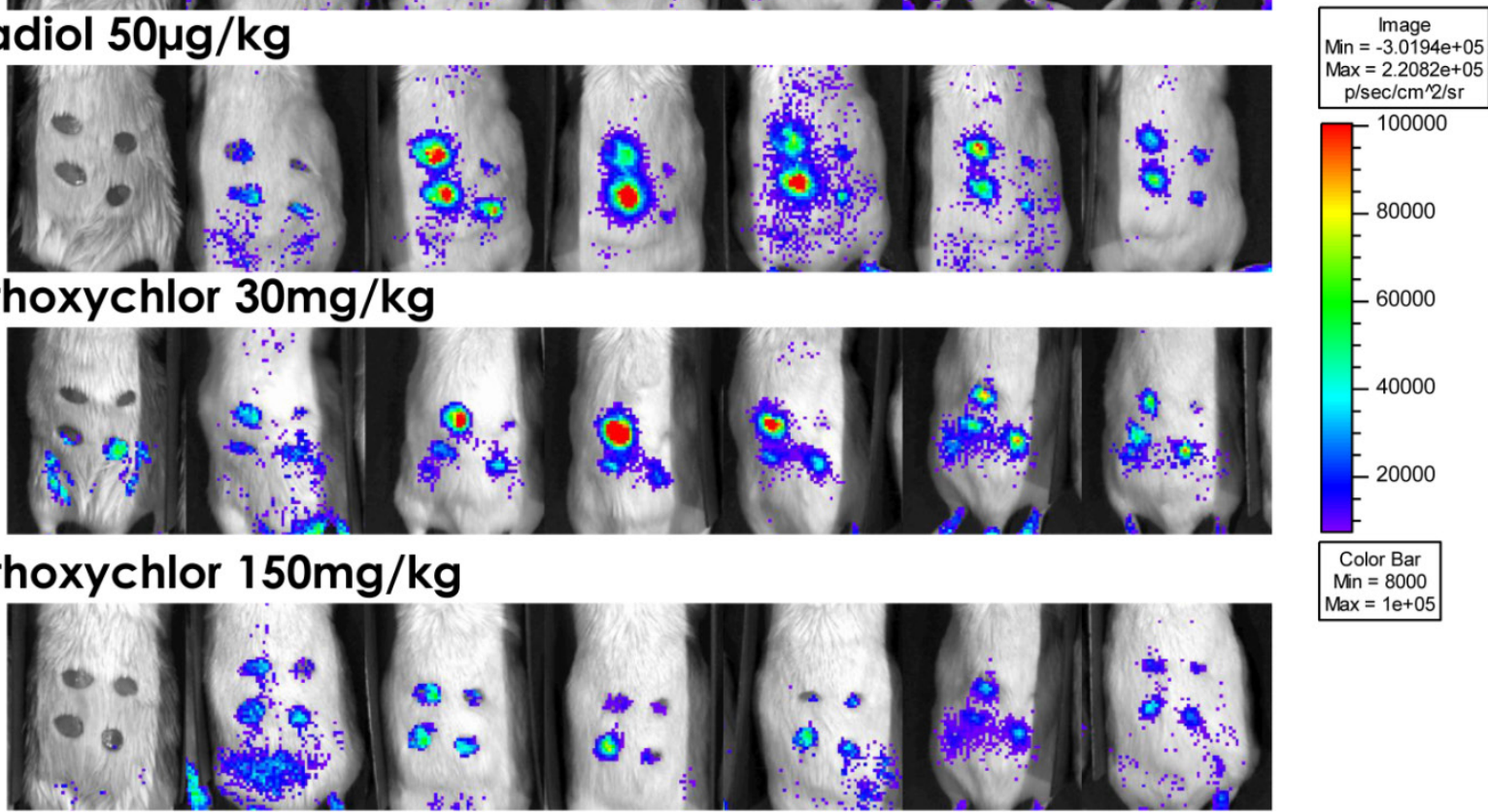

Figure I. VEGFR-2-Luc Reporter Gene Activity. VEGFR-2-Luc mediated gene expression in a mouse wound model. Mice were assigned to one of four treatment (groups
$\mathrm{n}=8 /$ group): safflower oil alone (Control), estradiol I7 $(50 \mu \mathrm{gg} / \mathrm{kg} / \mathrm{d})$, methoxychlor low dose $(30 \mathrm{mg} / \mathrm{kg} / \mathrm{d})$, and methoxychlor high dose $(150 \mathrm{mg} / \mathrm{kg} / \mathrm{d})$. Luciferase activity (i.e., photons/second) was quantified using Living Image software. To detect photonic emission, mice were injected with luciferin (I50 mg/kg in phosphate buffered saline i.p.). Ten minutes after luciferin administration, photons from wound sites were captured for 5 min using the IVIS I00TM biophotonic imaging system. A representative animal from each treatment group is shown on Days 0 to Day I4. The $\mathrm{min} / \mathrm{max}$ pseudo color values representing photon emission was normalized across all animals. 


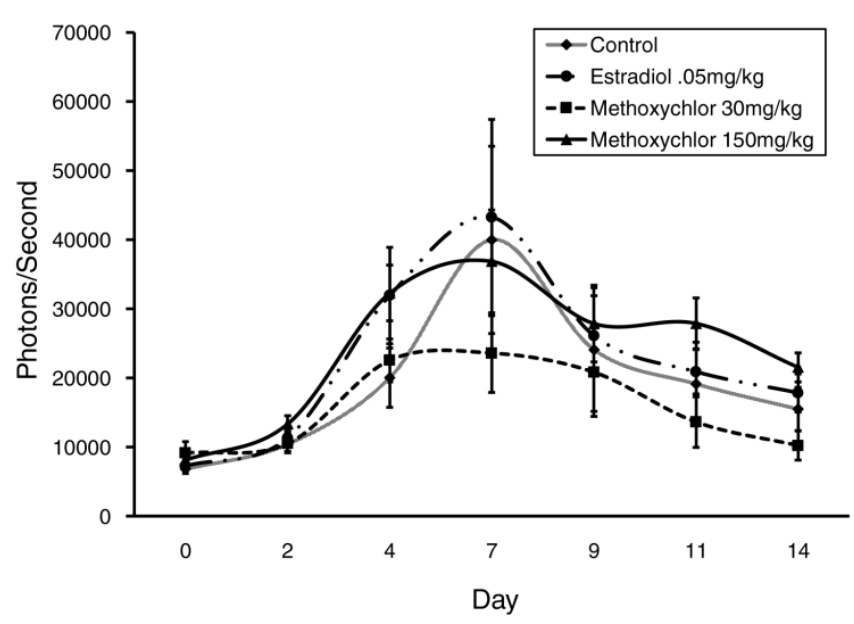

Figure 2. Wound Site Photonic Emission By Treatment. VEGFR-2-Luc-mediated gene expression from dermal wounds expressed as photons/second. Luciferase activity (i.e., photons/second) was quantified using Living Image ${ }^{\circledR}$ software. The Day 0 wound image was taken immediately following wound induction and subsequent images were taken on Days 2, 4, 7, 9, II, and I4 post-wounding. Data is shown as mean \pm standard error for each treatment group. Values between treatment groups were not significantly $(P>0.05)$ different.

Area under the curve (AUC) was analyzed for the presence of an overall treatment effect and determined not to be significant $(P>0.05)$ between treatment groups (Fig 3). However, since no significant difference was observed between treatments on any given day, data was pooled for each day and VEGFR-2-Luc-mediated gene expression was plotted over time. VEGFR-2-Luc reporter gene activity increased $(P<0.05)$ over time with peak values obtained on day 7 post wounding (Fig 4), which is consistent with results of similar studies $[27,30]$. Rate of wound closure is also shown in Figure 4 as percentage of day 0 wound area. All wounds from all animals were averaged together to create the rate of wound area closure depicted in Figure 4. There was no statistical difference in rate of wound closure between treatment groups. Although no significant difference in rate of wound closure was noticed between treatment groups, the profile of wound closure during the experiment provides a good reference of the wound healing process.

One of the main criteria that the wound healing mouse model used in this study was based on is the fact that VEGFR-2 is transcriptionally regulated by VEGF during angiogenesis [4, 5]. Hence, VEGFR-2-Luc reporter activity was utilized as an indirect measure of VEGF gene expression in these mice. To verify VEGF gene expression in the wound sites, semi-quantitative RT-PCR was employed on the tissue samples recovered from days 7 and 14. Endogenous VEGF gene expression in dermal wound tissue was confirmed by RT-PCR. No significant differences $(P>0.05)$ in VEGF gene expression was seen between day 7 and day 14 tissue samples. Therefore, data was pooled across day and analysed for an overall treatment effect. Figure 5 shows overall relative VEGF gene expression as a percentage of $18 \mathrm{~S}$ internal control. Neither dose of MXC had a significant effect $(P>0.05)$ on relative VEGF gene expression compared to the control group or to the estradiol $(50 \mu \mathrm{g} / \mathrm{kg})$ treated group. However, when compared to the control group the $\mathrm{E}_{2}$ treatment group significantly $(P<0.01)$ upregulated VEGF mRNA expression. The fact that $E_{2}$ upregulated endogenous VEGF, yet failed to have a significant effect on VEGFR-2-Luc reporter gene activity may suggest that a mouse wound model utilizing a VEGF-Luc reporter gene may be more applicable for screening chemicals with estrogenic tendencies.

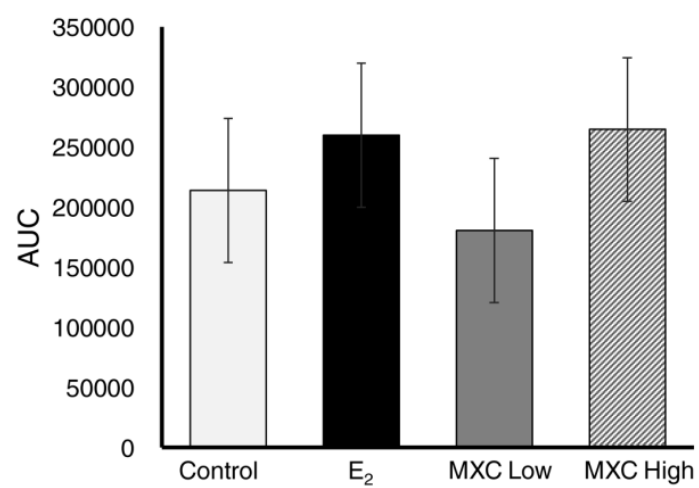

Figure 3. Area Under Curve by Treatment. VEGFR-2-Luc-mediated gene expression from dermal wounds expressed as area under the curve (AUC) to determine if an overall treatment effect was present. Control (safflower oil), $E_{2}$, estradiol $17 \beta$ $(50 \mu \mathrm{g} / \mathrm{kg} / \mathrm{d})$, MXC Low; methoxychlor low dose $(30 \mathrm{mg} / \mathrm{kg} / \mathrm{d})$, and MXC High; methoxychlor high dose $(150 \mathrm{mg} / \mathrm{kg} / \mathrm{d})$. There was no significant differences $(P>0.05)$ in AUC between treatment groups.

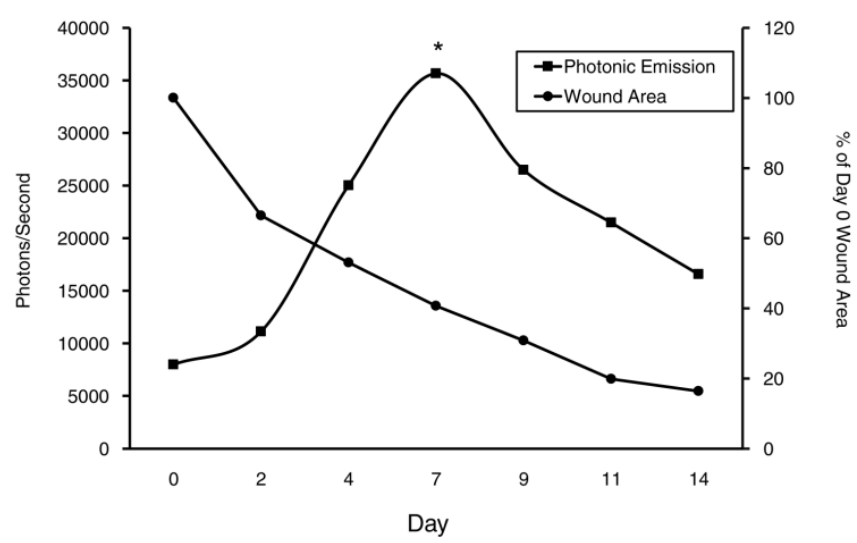

Figure 4. Photonic Emission and Percent Wound Area Across Treatments. VEGFR-2-Luc mediated gene expression from dermal wounds expressed as photons/second. Since no significant difference was observed between treatments on any given day, data was pooled for each day and VEGFR-2-Luc mediated gene expression plotted over time. The Day 0 wound image was taken immediately following wound induction and subsequent images were taken on Days 2, 4, 7, 9, II, and 14 post-wounding. Peak values were observed on $\mathrm{d} 7$ and were significantly different $(P<0.05)$ than other measured values. Percent wound closure is shown to show rate of wound area closure over time relative to VEGFR-2-Luc-mediated gene expression. 


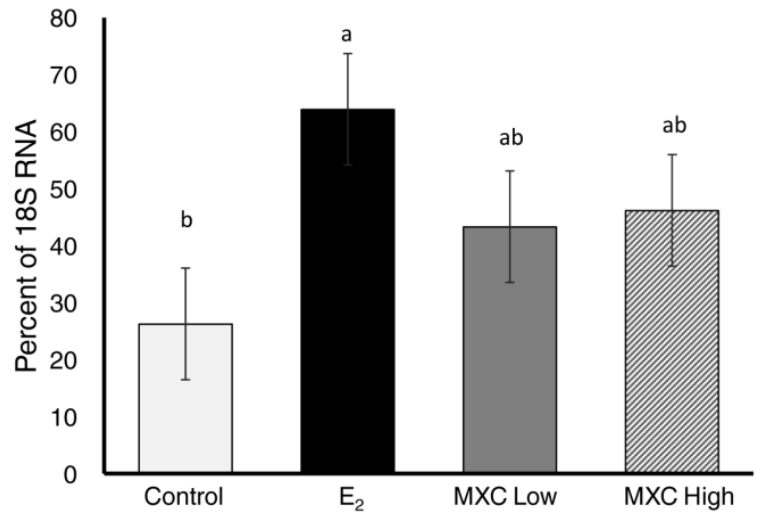

Figure 5. Relative VEGF mRNA Expression. Relative VEGF gene expression in dermal wounds measured by semi-quantitative RT-PCR. The ratio of VEGF mRNA expression to I8S RNA is expressed as a percentage. Control (safflower oil), $E_{2}$; estradiol I7 $(50 \mu \mathrm{g} / \mathrm{kg} / \mathrm{d})$, MXC Low; methoxychlor low dose $(30 \mathrm{mg} / \mathrm{kg} / \mathrm{d})$, and MXC High methoxychlor high dose ( $150 \mathrm{mg} / \mathrm{kg} / \mathrm{d})$. Different superscripts indicate significant differences between treatment groups. Data is presented as LS-Means \pm SEM where differences were considered significant when $P<0.05$.

\section{ER Alpha Gene Expression in Dermal Tissue}

It has been well established that MXC mimics $\mathrm{E}_{2}$ action in vivo and can cause adverse developmental and reproductive effects in rodents such as: embryo toxicity, precocious puberty, decreased fertility and ovarian atrophy. Chapin and colleagues [31] described changes in reproductive, immune and nervous system function in juvenile mice exposed to methoxychlor. Others have observed specific effects on male reproductive development in mice due to exposure during fetal life [32]. In a study performed by Chen et al., [33] several pyrethroid (permethrin, cypermethrin, deltamethrin) pesticides were found to induce MCF-7 cell (a breast cancer cell line) proliferation and that this effect was blocked by ICI 182,780, a potent estrogen receptor antagonist. Moreover, these same pyrethroid pesticides inhibited the binding of $\left[{ }^{3} \mathrm{H}\right]$-estradiol to the estrogen receptor [33]. Additionally, estrogen-stimulated release of growth factors (e.g., transforming growth factor; TGF-a, epidermal growth factor; EGF, and insulin-like growth factor; IGF-1) can act synergistically with estrogenic compounds to accelerate cancer cell growth [34] and enhance ER/ERE-mediated transcriptional processes [34-36].

In the case of dermal wound healing it is important to note the importance of estrogen receptors in dermal tissue. There is ample evidence demonstrating receptor distribution and related actions to show that estrogens have a direct influence on all elements of skin [14]. Ashcroft et al. demonstrated that applying estrogen topically to murine animal models accelerates cutaneous wound healing of acute incisional wounds, presumably in part due to estrogens pro-angiogenic tendencies [37].

Oral treatment delivery, which mimics real world uptake of MXC (i.e. oral consumption of pesticide treated produce), would lead to MXC being metabolized to HPTE in the liver. The methoxychlor metabolite HPTE has been shown to be an ERa agonist $[38,39]$. The presence of estrogen receptor a (ERa) in dermal tissue was confirmed by mRNA expression. No significant differences of ERa mRNA expression $(P>0.05)$ between treatment or days post wounding were noted (Fig 6). However, the confirmation of ERa mRNA expression verifies the presence of an essential component of the pathway involved in estrogen signalling affecting VEGF/VEGFR-2 expression.

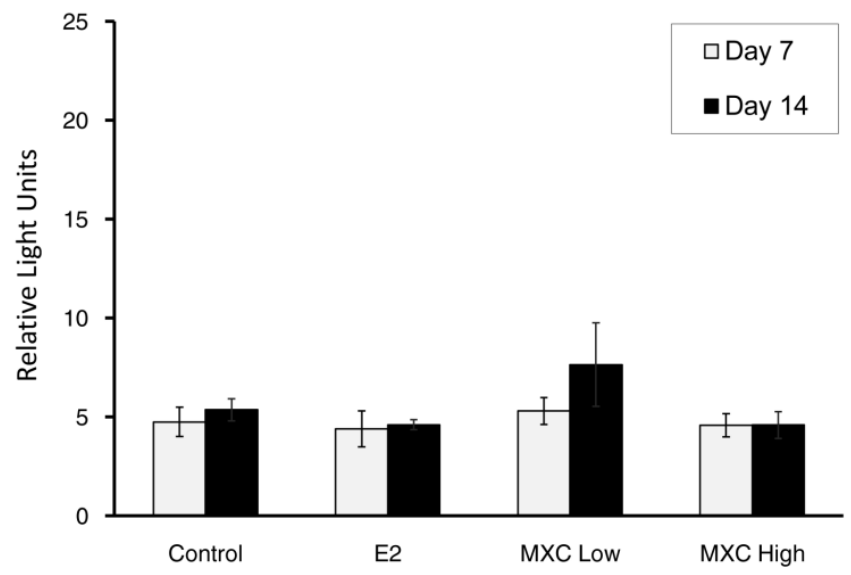

Figure 6. ER $\alpha$ Gene Expression. Estrogen Receptor $\alpha(E R \alpha)$ mRNA expression in dermal tissue samples was detected using the XpressPackTM ERa (human, mouse, rat) mRNA Expression Analysis Kit and the XpressPack ${ }^{T M}$ Luminescent Detection System (Chemicon International, Temecula, CA). Results are expressed as relative light units (RLUs). Each treatment: Control, E2, methoxychlor low dose (MXC Low), and methoxychlor high dose (MXC High) is shown with day 7 mean ER expression in white and day 14 mean ER expression in black. No statistical differences $(P>0.05)$ were measured between treatment or days post wounding.

\section{Histological Analysis}

It has long been recognized that estrogens stimulate the synthesis and turnover of collagen in animal skin $[14,40,41]$. Hence, in this experiment collagen deposition was analysed by trichrome staining of histological samples of wound tissue. Histological analysis was performed on each wound sample from each animal. All samples showed ample collagen content in wound sites indicated by the blue tissue of samples A-D in (Fig 7 A-D). However, no observable difference in collagen deposition was noted between treatments or days post wounding in analyzed wound tissue samples. Vascular cell composition was analyzed via endothelial cell stain F-8. Evidence of vascular cell deposition was evident in samples E-H in (Fig. 7 E-H) indicated by the brown colored areas, yet no differences were observed in vascular cell deposition between treatments or days post wounding in analyzed wound samples. 

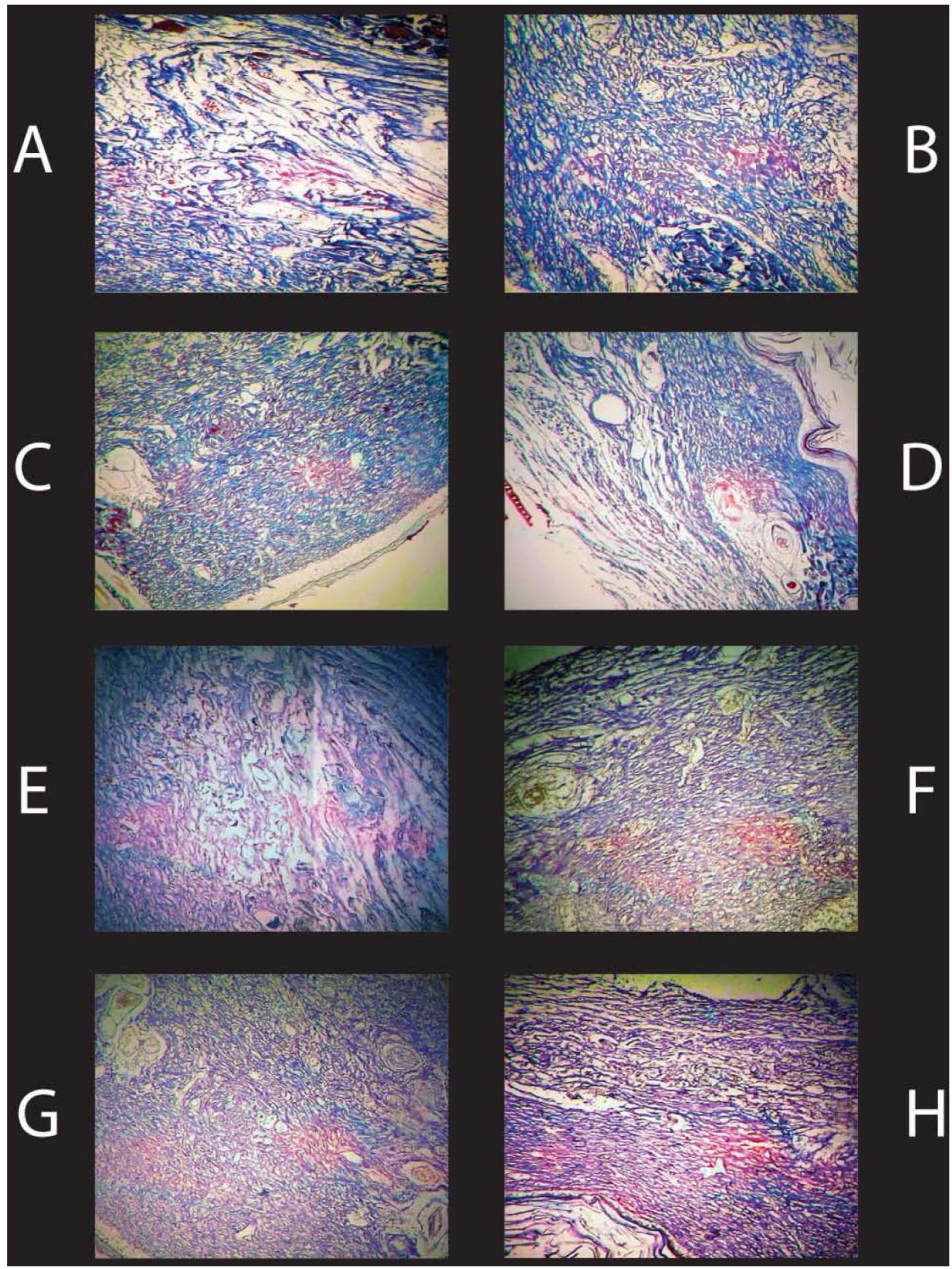

Figure 7. Histological Analysis of Day 7 Wound Samples. Histological samples of Day 7 wound tissue at 40X magnification. A-D represent samples stained with Tri-Chrome. [A] Wound tissue from a representative control animal, $[B] E_{2}(50 \mu \mathrm{g} / \mathrm{kg} / \mathrm{d})$, [C] MXC Low dose $(30 \mathrm{mg} / \mathrm{kg} / \mathrm{d})$, [D] MXC High ( $\left.150 \mathrm{mg} / \mathrm{kg} / \mathrm{d}\right)$. Collagen is stained blue in the samples. There were no noted differences in collagen content between treatment groups. E-H represent samples stained with F-8. [E] Control, [F] E2, [G] MXC Low (30mg/kg/d), $[\mathrm{H}]$ MXC High $(150 \mathrm{mg} / \mathrm{kg} / \mathrm{d})$. Vascular cells are stained brown in the samples. There were no noted differences in vascular cell staining between treatment groups.

\section{Conclusions}

This study was undertaken to investigate the relevance and value of using biophotonics and real-time imaging technology as a tool to screen for compounds with estrogenic activities. Changes in
VEGFR-2-Luc gene activity associated with the dermal wound healing process were able to be measured via photonic emission. The increase in vasculature recruitment and formation is paralleled by the increase of VEGFR-2-Luc activity with a peak on day 7. However, estrogen/methoxychlor did not significantly 
alter wound healing mediated VEGFR-2-Luc gene expression patterns compared to controls. Monitoring compounds with estrogenic activity with this transgenic wound model applied in this study proved to be insufficient in terms of significant differences in wound healing mediated VEGFR-2-Luc reporter gene activity between treatment groups. The $E_{2}$ treated animals did show an increase in endogenous VEGF mRNA compared to controls, yet this increase was not paralleled by VEGFR-2-Luc driven photonic emission. Conversely, MXC did not alter VEGF mRNA. This could have arisen from any number of reasons including the fact that this model employed monitoring estrogen's effect on VEGF indirectly through VEGFR-2. A more relevant model may employ a transgenic VEGF-Luc mouse, which was not made available at the time these studies were undertaken. It is also important to note that although MXC is an estrogenic compound it is considered a weak estrogen [42], and the concentrations used in this study may have been such that their bioactivity was too low to elicit an estrogenic response via the VEGFR-2-Luc wound healing reporter system. Although dermal wound healing is affected by estrogens [37, 43, 44], the estrogen-VEGF system associated with dermal wound healing may not have been the ideal system to target as a screen for estrogenic compounds.

\section{Acknowledgments}

This work was funded by the United States Department of Agriculture, Agricultural Research Station (Biophotonics Research Initiative, grant \# 58-6402-3-0120).

\section{Authors' contributions}

RCY conceived, designed, and performed the experiment as well as drafted the manuscript; all data acquisition and analysis was also performed by RCY. MM participated with the biophotonic imaging and animal maintenance. JMF provided guidance with the submission process and drafting of the manuscript. PLR and STW aided in conception of the study, provided guidance and helped with experimental design. All authors have discussed the results and reviewed the manuscript. All authors read and approved the final manuscript.

\section{Conflict of interest}

All aspects of this study were performed in our laboratories. The listed authors have read the final report and have agreed to its submission and publication. The authors claim no conflicts of interest.

\section{References}

1. Singer AJ, Clark RA. Cutaneous wound healing. N Engl J Med. 1999; 341: 738-46.
2. Ferrara N, Davis-Smyth T. The biology of vascular endothelial growth factor. Endocr Rev. 1997; 18: 4-25.

3. Shalaby F, Rossant J, Yamaguchi TP, Gertsenstein M, Wu XF, Breitman ML, et al. Failure of blood-island formation and vasculogenesis in Flk-1-deficient mice. Nature. 1995; 376: 62-6.

4. Wang D, Donner DB, Warren RS. Homeostatic modulation of cell surface KDR and Flt1 expression and expression of the vascular endothelial cell growth factor (VEGF) receptor mRNAs by VEGF. J Biol Chem. 2000; 275: 15905-11.

5. Regnault TR, Orbus RJ, de Vrijer B, Davidsen ML, Galan HL, Wilkening RB, et al. Placental expression of VEGF, PIGF and their receptors in a model of placental insufficiency-intrauterine growth restriction (PI-IUGR). Placenta. 2002; 23: $132-44$.

6. Dumont DJ, Fong GH, Puri MC, Gradwohl G, Alitalo K, Breitman ML. Vascularization of the mouse embryo: a study of flk-1, tek, tie, and vascular endothelial growth factor expression during development. Dev Dyn. 1995; 203 : 80-92.

7. Veikkola T, Alitalo K. VEGFs, receptors and angiogenesis. Semin Cancer Biol. 1999; 9: 211-20.

8. Hyder SM, Chiappetta C, Murthy L, Stancel GM. Selective inhibition of estrogen-regulated gene expression in vivo by the pure antiestrogen ICI 182,780. Cancer Res. 1997; 57: 2547-9.

9. Ruohola JK, Valve EM, Karkkainen MJ, Joukov V, Alitalo K, Harkonen PL. Vascular endothelial growth factors are differentially regulated by steroid hormones and antiestrogens in breast cancer cells. Molecular and cellular endocrinology. 1999; 149: 29-40.

10. Hyder SM, Nawaz Z, Chiappetta C, Stancel GM. Identification of functional estrogen response elements in the gene coding for the potent angiogenic factor vascular endothelial growth factor. Cancer Res. 2000; 60: 3183-90.

11. Dardes RC, Schafer JM, Pearce ST, Osipo C, Chen B, Jordan VC. Regulation of estrogen target genes and growth by selective estrogen-receptor modulators in endometrial cancer cells. Gynecol Oncol. 2002; 85: 498-506.

12. Bogin L, Degani H. Hormonal regulation of VEGF in orthotopic MCF7 human breast cancer. Cancer Res. 2002; 62: 1948-51.

13. Stoner M, Wang F, Wormke M, Nguyen T, Samudio I, Vyhlidal C, et al. Inhibition of vascular endothelial growth factor expression in HEC1A endometrial cancer cells through interactions of estrogen receptor alpha and Sp3 proteins. J Biol Chem. 2000; 275: 22769-79.

14. Thornton MJ. The biological actions of estrogens on skin. Exp Dermatol. 2002; 11: 487-502.

15. Smith QT, Allison DJ. Changes of collagen content in skin, femur and uterus of 17-beta-estradiol benzoate-treated rats. Endocrinology. 1966; 79: 486-92.

16. Brincat MP. Hormone replacement therapy and the skin. Maturitas. 2000; 35: 107-17.

17. Uzuka M, Nakajima K, Mori Y. Estrogen receptor in the mouse skin. Biochim Biophys Acta. 1978; 544: 329-37.

18. Hasselquist MB, Goldberg N, Schroeter A, Spelsberg TC. Isolation and characterization of the estrogen receptor in human skin. J Clin Endocrinol Metab. 1980; 50: 76-82.

19. Gagliardi AR, Hennig B, Collins DC. Antiestrogens inhibit endothelial cell growth stimulated by angiogenic growth factors. Anticancer Res. 1996; 16: 1101-6.

20. Lachgar S, Charveron M, Sarraute J, Gall Y, Bonafe JL. Anti-androgens and estrogens: modulators of VEGF expression in cultured hair dermal papilla cells. Exp Dermatol. 1999; 8: 336-8.

21. Garey J, Wolff MS. Estrogenic and antiprogestagenic activities of pyrethroid insecticides. Biochem Biophys Res Commun. 1998; 251: 855-9.

22. Aprea C, Sciarra G, Sartorelli P, Mancini R, Di Luca V. Environmental and biological monitoring of exposure to mancozeb, ethylenethiourea, and dimethoate during industrial formulation. J Toxicol Environ Health A. 1998; 53: 263-81.

23. Cole DC, Carpio F, Julian J, Leon N. Assessment of peripheral nerve function in an Ecuadorian rural population exposed to pesticides. J Toxicol Environ Health A. 1998; 55: 77-91.

24. [Internet] United States Agency for Toxic Substances and Disease Registry. Toxicological profile for methoxychlor. http://purl.fdlp.gov/GPO/gpo31609.

25. Kupfer D, Bulger WH, Theoharides AD. Metabolism of methoxychlor by hepatic P-450 monooxygenases in rat and human. 1. Characterization of a novel catechol metabolite. Chem Res Toxicol. 1990; 3: 8-16.

26. Walters LM, Rourke AW, Eroschenko VP. Purified methoxychlor stimulates the reproductive tract in immature female mice. Reprod Toxicol. 1993; 7: 599-606.

27. Zhang N, Fang Z, Contag PR, Purchio AF, West DB. Tracking angiogenesis induced by skin wounding and contact hypersensitivity using a Vegfr2-luciferase transgenic mouse. Blood. 2004; 103: 617-26.

28. Draper BK, Davidson MK, Nanney LB. MMPs and TIMP-1 are differentially expressed between acute murine excisional and laser wounds. Lasers Surg Med. 2002; 30: 106-16.

29. Carson FL, Hladik C. Histotechnology: a self-instructional text; 3rd ed. Chicago: ASCP Press; 2009.

30. Ryan PL, Youngblood RC, Harvill J, Willard ST. Photonic monitoring in real time of vascular endothelial growth factor receptor 2 gene expression under relaxin-induced conditions in a novel murine wound model. Ann N Y Acad Sci. 2005 ; 1041: 398-414.

31. Chapin RE, Harris MW, Davis BJ, Ward SM, Wilson RE, Mauney MA, et al. The effects of perinatal/juvenile methoxychlor exposure on adult rat nervous, 
immune, and reproductive system function. Fundam Appl Toxicol. 1997; 40: $138-57$.

32. Welshons WV, Nagel SC, Thayer KA, Judy BM, Vom Saal FS. Low-dose bioactivity of xenoestrogens in animals: fetal exposure to low doses of methoxychlor and other xenoestrogens increases adult prostate size in mice. Toxicol Ind Health. 1999; 15: 12-25.

33. Chen H, Xiao J, Hu G, Zhou J, Xiao H, Wang X. Estrogenicity of organophosphorus and pyrethroid pesticides. J Toxicol Environ Health A. 2002; 65: 1419-35

34. Ignar-Trowbridge DM, Pimentel M, Parker MG, McLachlan JA, Korach KS. Peptide growth factor cross-talk with the estrogen receptor requires the A/B domain and occurs independently of protein kinase $C$ or estradiol. Endocrinology. 1996; 137: 1735-44

35. Ignar-Trowbridge DM, Teng CT, Ross KA, Parker MG, Korach KS, McLachlan JA. Peptide growth factors elicit estrogen receptor-dependent transcriptional activation of an estrogen-responsive element. Mol Endocrinol. 1993; 7: 992-8.

36. El-Tanani MK, Green CD. Interaction between estradiol and growth factors in the regulation of specific gene expression in MCF-7 human breast cancer cells. J Steroid Biochem Mol Biol. 1997; 60: 269-76.

37. Ashcroft GS, Greenwell-Wild T, Horan MA, Wahl SM, Ferguson MW. Topical estrogen accelerates cutaneous wound healing in aged humans associated with an altered inflammatory response. Am J Pathol. 1999; 155: 1137-46.

38. Gould JC, Leonard LS, Maness SC, Wagner BL, Conner K, Zacharewski T, et al. Bisphenol A interacts with the estrogen receptor alpha in a distinct manner from estradiol. Molecular and cellular endocrinology. 1998; 142: 203-14

39. Yoon K, Pellaroni L, Ramamoorthy K, Gaido K, Safe S. Ligand structure-dependent differences in activation of estrogen receptor alpha in human HepG2 liver and U2 osteogenic cancer cell lines. Molecular and cellular endocrinology. 2000; 162: 211-20.

40. Henneman DH. Effect of estrogen on in vivo and in vitro collagen biosynthesis and maturation in old and young female guinea pigs. Endocrinology. 1968; 83: $678-90$.

41. Sobel H, Lee KD, Hewlett MJ. Effect of estrogen on acid glycosaminoglycans in skin of mice. Biochim Biophys Acta. 1965; 101: 225-9.

42. Shelby MD, Newbold RR, Tully DB, Chae K, Davis VL. Assessing environmental chemicals for estrogenicity using a combination of in vitro and in vivo assays. Environmental health perspectives. 1996; 104: 1296-300.

43. Ashcroft GS, Dodsworth J, van Boxtel E, Tarnuzzer RW, Horan MA, Schultz GS, et al. Estrogen accelerates cutaneous wound healing associated with an increase in TGF-beta1 levels. Nat Med. 1997; 3: 1209-15.

44. Ashcroft GS, Mills SJ, Lei K, Gibbons L, Jeong MJ, Taniguchi M, et al. Estrogen modulates cutaneous wound healing by downregulating macrophage migration inhibitory factor. J Clin Invest. 2003; 111: 1309-18. 